\title{
Investigations on the Effect of Land Leveling Indices on Soil Moisture Distribution in Cotton Fields
}

\author{
P. S. Kanannavar, R. Vasantgouda*, Kumar Lamani, \\ B. C. Punitha and U. K. Shanawad \\ IWMRC, Belavatagi, University of Agricultural Sciences, Dharwad, India \\ *Corresponding author
}

\begin{abstract}
A B S T R A C T
\section{Keywords}

Soil moisture, land levelling index, spatial variability, cotton

Article Info

Accepted:

10 April 2020

Available Online:

10 May 2020

Land development is one of the prime components of sustainable farming. Unevenness of agricultural fields leads to the in-efficient use of irrigation water, which in turn reduces the yield and farm income. Levelling index, which is a dynamic factor, determines the quality and accuracy of land levelling. Land development/levelling is having enormous impact on moisture storage and distribution in the field both spatially and temporally, crop growth, yields and irrigation water saving. Therefore, it is imperative to study the impact of levelling indices on soil moisture distribution in fields. An experiment was conducted in the research farms of Irrigation Water Management Research Center (IWMRC), Belvatagi, University of Agricultural Sciences (UAS) Dharwad during Rabi 2018 to investigate the effect of land levelling indices on soil moisture distribution in Cotton fields. The results indicated spatial variability with respect to levelling indices and soil moisture in the same fields with average LI ranging from $1.57 \mathrm{~cm}$ to $3.50 \mathrm{~cm}$ and average soil moisture ranging from $28.63 \%$ to $31.87 \%$. Also, it was found that lower the LIs higher the soil moisture i.e. soil moisture increased with the better quality of land leveling irrespective of the cotton varieties. Soil moisture distribution variability can be reduced by better quality of land leveling.
\end{abstract}

\section{Introduction}

In agriculture, land development plays a key role because undulating topography of the soil surface has a major impact on the germination, water saving and crop yield. Traditional methods of leveling lands are more cumbersome and time-consuming. A significant (20-25\%) amount of irrigation water is lost during its application at the farm due to poor farm design and unevenness of the field (Cook and Peikert, 1960). Better land levelling saves irrigation water and facilitates field operation and increases yield (Rickman, 2002). For an efficient irrigation system the level difference between high and low spots of a field should not exceed $20 \mathrm{~mm}$ whereas under actual field conditions, a difference of 50 to $100 \mathrm{~mm}$ is very common. Hence dynamic levelling parameters such as 
standard deviation of elevations and levelling index determine the accuracy of levelling which affects soil moisture distribution and its variability. For agricultural sustainability the variability needs to be avoided. So the present study during Rabi 2018 was conducted to investigate the effect of land levelling indices on soil moisture distribution in Cotton fields of Irrigation Water Management Research Center (IWMRC), Belvatagi, University of Agricultural Sciences (UAS) Dharwad, Karnataka.

\section{Materials and Methods}

In this study, a multi-location trial (MLT) on cotton was taken up in vertisols at IWMRC at
Agricultural Research Station Belavatagi as shown in Fig.1. MLT was with 12 cotton varieties $V_{1}$ to $V_{12}$ with3 replications $R_{1}, R_{2}$ and $\mathrm{R}_{3}$ and statistical design RCBD. Topographic survey was done to find out levelling indices (LIs) of the field as shown in Fig.2. Engineering parameters of land levelling indices and soil moisture variations as affected by LIs was observed. 5 irrigations were given with depths of $68 \mathrm{~mm}, 47 \mathrm{~mm}, 77$ $\mathrm{mm}, 47 \mathrm{~mm}$ and $97 \mathrm{~mm}$, respectively. After an irrigation event of $68 \mathrm{~mm}$, soil moisture (0$10 \mathrm{~cm}$ depth) was measured with the help of theta probe. (Fig.3.) The levelling indices of the plots were calculated during the study using the formula given by Agarwal and Goel. (1981)

$$
\text { Leveling index }=\frac{\sum \text { Numerical difference between the designed and existing grid levels }}{\text { Number of grid points }}
$$

The impact of levelling index was observed with respect to soil moisture distribution and its variations in the field after an irrigation event. All the 12 varieties were sown on 25 10-2018.

\section{Results and Discussion}

From Table.1It was observed that the spatial variability with respect to levelling indices and soil moisture in the same fields with average LI ranges from $1.57 \mathrm{~cm}$ to $3.50 \mathrm{~cm}$ and average soil moisture ranging from 28.63 $\%$ to $31.87 \%$. Figures 4 to 15 represent Levelling index Versus Soil moisture curves for all 12 varieties show the effect of LI on soil moisture distribution. From all the curves it was observed that the general trend of decreasing soil moisture with increase in Levelling index.

Table.1 Land leveling index and soil moisture for different varieties of cotton

\begin{tabular}{|c|c|c|c|c|c|c|c|}
\hline \multirow{2}{*}{ Sl.No. } & \multirow{2}{*}{ Variety } & \multicolumn{3}{|c|}{ Levelling index,cm } & \multicolumn{3}{c|}{ Soil moisture (V/V), \% } \\
\cline { 2 - 7 } & & $\mathrm{R}_{1}$ & $\mathrm{R}_{2}$ & $\mathrm{R}_{3}$ & $\mathrm{R}_{1}$ & $\mathrm{R}_{2}$ & $\mathrm{R}_{3}$ \\
\hline $\mathbf{1}$ & $\mathrm{V}_{1}$ & 1.78 & 1.85 & 2.49 & 34.12 & 29.41 & 25.01 \\
\hline $\mathbf{2}$ & $\mathrm{V}_{2}$ & 2.94 & 2.22 & 2.07 & 30.43 & 28.74 & 32.73 \\
\hline $\mathbf{3}$ & $\mathrm{V}_{3}$ & 2.15 & 2.69 & 5.67 & 28.79 & 36.47 & 30.34 \\
\hline $\mathbf{4}$ & $\mathrm{V}_{4}$ & 2.05 & 1.14 & 1.43 & 31.66 & 32.08 & 31.49 \\
\hline $\mathbf{5}$ & $\mathrm{V}_{5}$ & 2.37 & 3.16 & 2.15 & 31.28 & 25.13 & 31.36 \\
\hline $\mathbf{6}$ & $\mathrm{V}_{6}$ & 1.78 & 3.26 & 2.02 & 30.38 & 29.96 & 29.91 \\
\hline $\mathbf{7}$ & $\mathrm{V}_{7}$ & 1.78 & 1.09 & 1.85 & 28.36 & 34.33 & 28.63 \\
\hline $\mathbf{8}$ & $\mathrm{V}_{8}$ & 1.28 & 2.89 & 1.48 & 27.67 & 27.58 & 30.73 \\
\hline $\mathbf{9}$ & $\mathrm{V}_{9}$ & 2.17 & 1.56 & 1.48 & 28.28 & 27.27 & 32.13 \\
\hline $\mathbf{1 0}$ & $\mathrm{V}_{10}$ & 1.78 & 1.28 & 2.22 & 24.36 & 31.04 & 30.48 \\
\hline $\mathbf{1 1}$ & $\mathrm{V}_{11}$ & 0.94 & 2.67 & 2.42 & 34.97 & 26.23 & 27.90 \\
\hline $\mathbf{1 2}$ & $\mathrm{V}_{12}$ & 2.64 & 2.22 & 1.80 & 29.62 & 27.89 & 34.00 \\
\hline
\end{tabular}




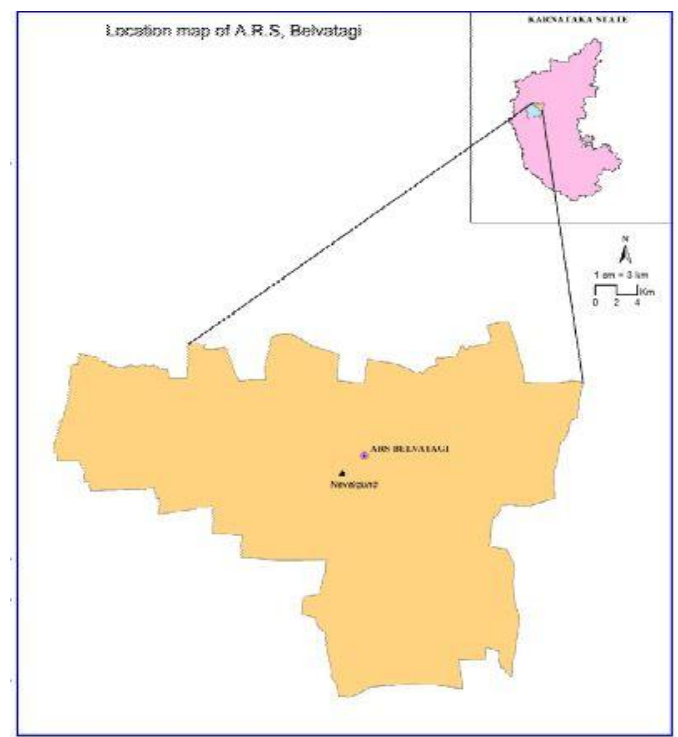

Fig.1 Location map of study area

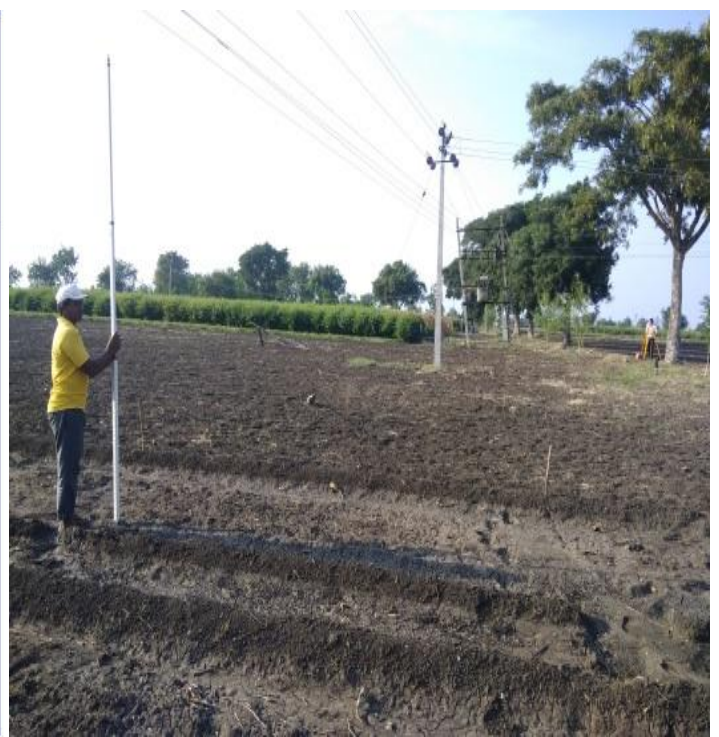

Fig.2 Topographic survey

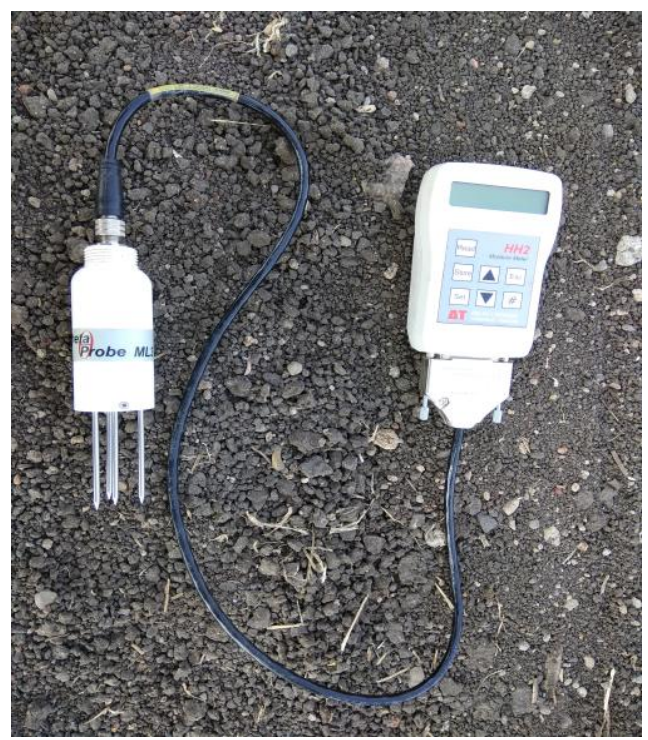

Fig.3 Theta probe for soil moisture measurement

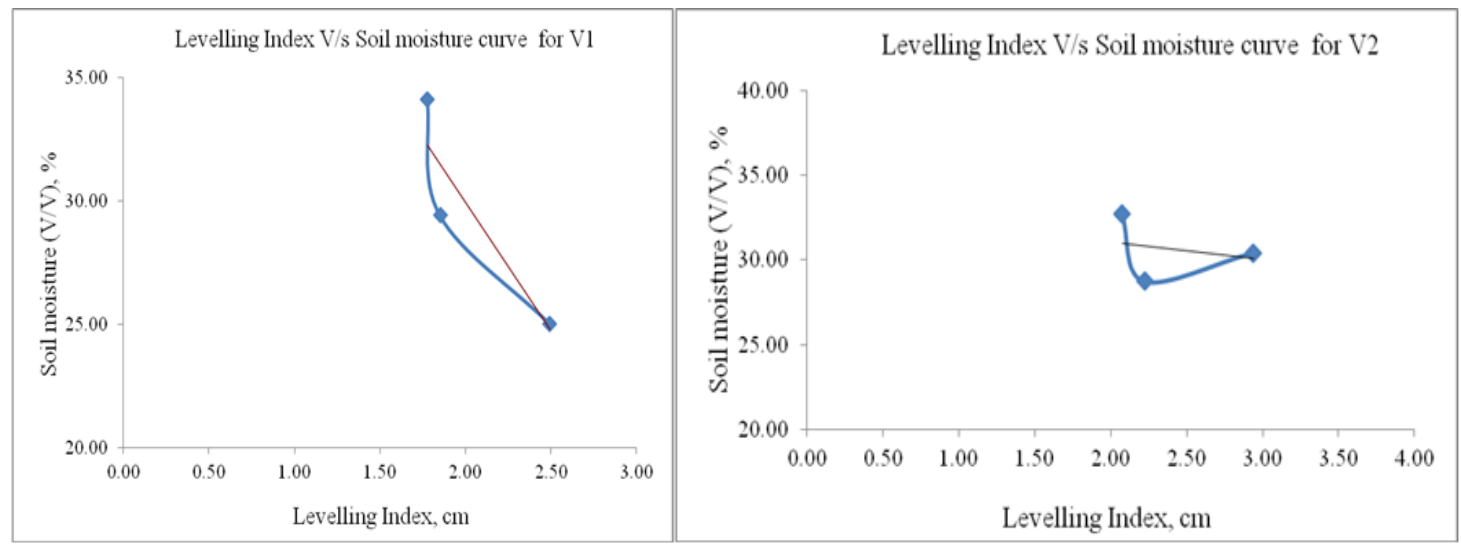


Int.J.Curr.Microbiol.App.Sci (2020) 9(5): 1344-1348

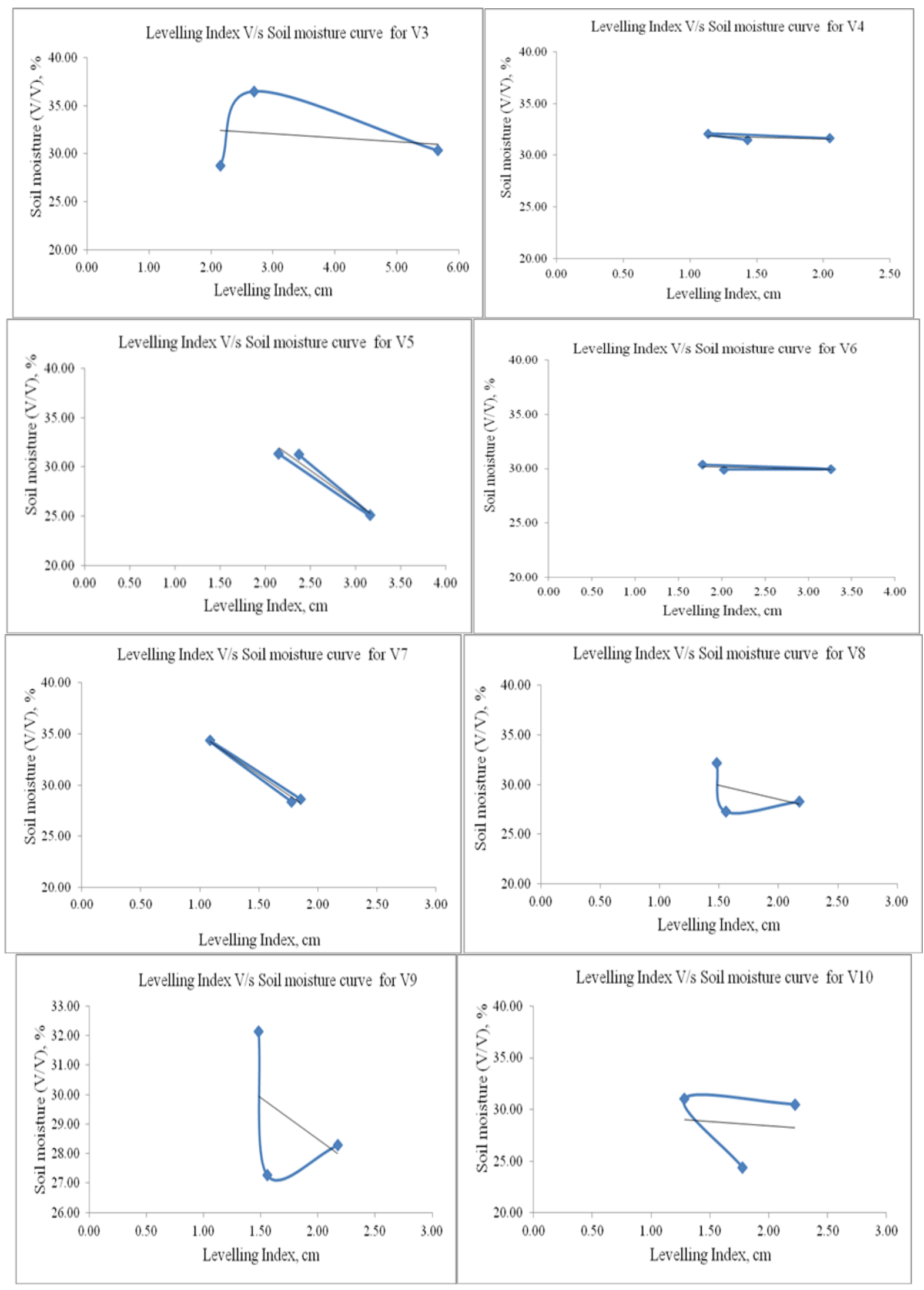




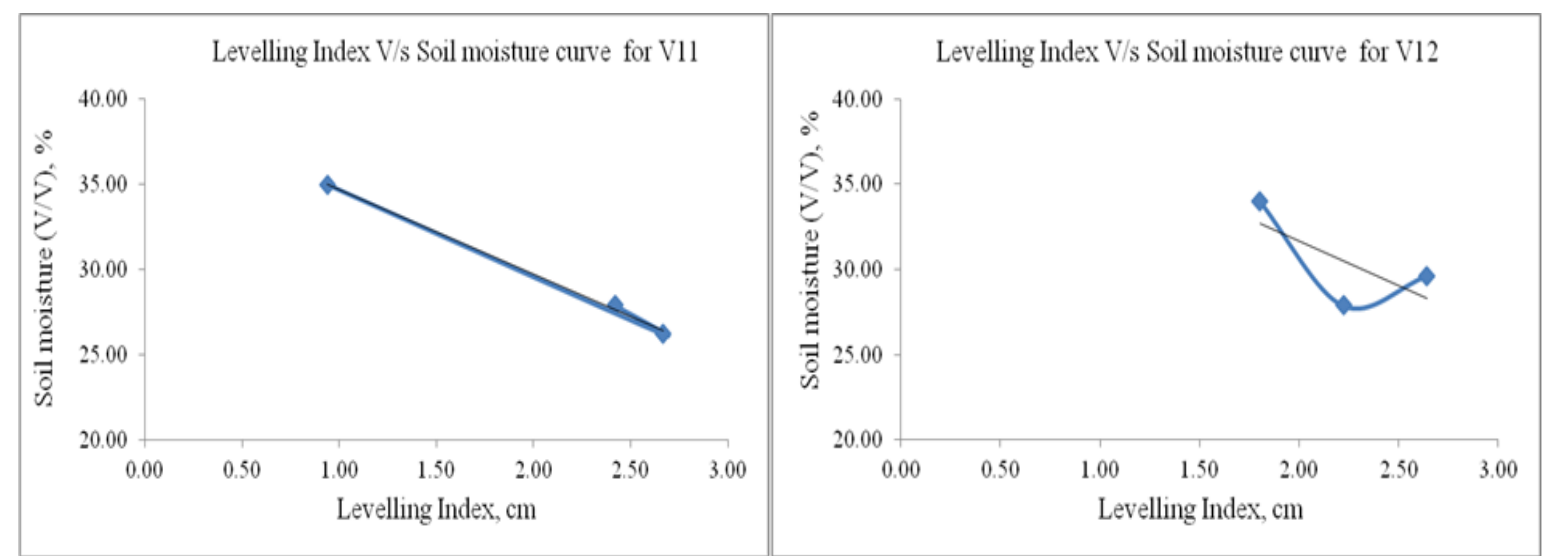

Figures.4-15 Levelling index Versus Soil moisture curves for Varieties of cotton $V_{1}$ to $V_{12}$

The increase in levelling index indicates the decrease the quality of levelling conditions with undulating micro topography of the fields. Thus the effect of microtopography of the field affects soil moisture distribution and ultimately irrigation performance. The same findings were stated by Playan et al., (1996) and Cazanescu et al., (2010).

The variability of levelling indices exists in the same field indicating undulating micro topography. It is found that lower the LIs higher the soil moisture irrespective of varieties of cotton. Land levelling quality is of high importance in intensive agriculture conditions to provide optimal and equal conditions to the crops during yielding and growing

\section{References}

Agarwal, M.C and Goel, A. C., 1981.Effect of field levelling quality on irrigation efficiency and crop yield. Agricultural Water Management ,4: 457-464

Cazanescu, S., Doru, M. and Radu, M., 2010, Modern technology for land levelling based on a 3-D scanner. Res. J. Agric. Sci., 42 (3): 471-478.

Cook, R. L. and F.W. Peikert, 1960. A comparison of tillage implement. The Journal of American Society of Agricultural Engineers. Vol. 31: 211214.

Playan, E., Faci, J. M. and Serreta, A., 1996, Characterizing micro topographical effects on level-basin irrigation performance. Agric. Water Man., 29:129-145.

Rickman, J. F., 2002. "Manual for laser land leveling".Rice-Wheat Consortium Technical Bulletin Series 5. New Delhi110 012, India: Rice-Wheat Consortium for the Indo-Gangetic plains, p24.

\section{How to cite this article:}

Kanannavar. P. S., R. Vasantgouda, Kumar Lamani, B. C. Punitha and Shanawad. U. K. 2020. Investigations on the Effect of Land Leveling Indices on Soil Moisture Distribution in Cotton Fields. Int.J.Curr.Microbiol.App.Sci. 9(05): 1344-1348. doi: https://doi.org/10.20546/ijcmas.2020.905.151 